\title{
nature

\section{Recipe for disaster}

The European Commission's (EC) Joint Research Centre recently published a report detailing the decline of genetically modified organism (GMO) research in Europe entitled Review of GMOs under Research and Development and in the Pipeline in Europe (p. 468). Amongst its findings was the fact that two-thirds of large European companies that had been involved in genetically modified (GM) crop development have cancelled substantial projects since 1998. An associated observation-whether this is a cause or an effect is uncertain-is that while the number of US field trials on GM crops has been running between 900 and 1,100 per year since 1998, in Europe the number peaked at 234 in 1998 and fell to just 33 last year.

For European researchers and businesses alike, these numbers are hard to swallow. So it is with some hesitation that Nature Biotechnology has agreed to publish the recipe for this particular disaster. The dish is, in essence, a pie in which an expensive and nutritious filling is covered by a largely impenetrable crust.

Cooking time:

This is a slow cooker. It probably takes about ten years to get the desired half-baked results.

For the filling, you will need:

- Several centers of excellence, such as the John Innes Centre in Norwich, the Max Planck Institute for Plant Breeding Research in Cologne, and the Swiss Federal Institute of Technology of Plant Sciences in Zurich, as well as a strong tradition of plant science elsewhere;

- Pioneering researchers, such as Jeff Schell and Marc van Montagu (Ti plasmid inventors), Ingo Potrykus (golden rice), Lothar Willmitzer (carbohydrate metabolism), Dick Flavell (cloning of plant DNA in bacteria), and many others;

- A rich selection of startup companies of various vintagesAgricultural Genetics, Plant Genetic Systems, Florigene, Axis Genetics, Keygene, Mendel Biotechnology, Rhobio, Metanomics, and SunGene;

- A liberal sprinkling of large agrochemical companies, including ICI Seeds, Ciba-Geigy Seeds (now Syngenta), Rhône-Poulenc, Bayer CropScience, AgrEvo, and BASF Plant Science.

Mix all the ingredients together, so that you create a healthy and dynamic biotechnology sector with tremendous potential to produce competitive companies and products. Bring out the entrepreneurial flavor by encouraging small agbiotechnology startups and research through EC funding programs (BAP, BEP, BRIDGE,
BIOTECH, Framework IV, Framework V). Stir constantly with words that indicate you are trying to promote innovation.

The crust should be made precisely in parallel with the filling but in an entirely separate part of the kitchen.

For the crust, you will need:

- The 90/220/EEC Directive for deliberate release of GM organisms;

- A soup of horizontal European legislation and national process that has been left to stew in its own administrative juices;

- A de facto moratorium on the commercial release of all genetically modified plants based on national self interest;

- A sprinkling of largely data-free high-visibility scientific papers;

- A spare Directive 2001/18/EC, just in case the first one fails

Sift the Directive through the fine mesh of European Parliamentary review committees to remove any residual trace of scientific validity. Add the Directive to the legislative soup. Leave to set for several years until GM products come to the market. Just as the products emerge, introduce the moratorium. Replace the original Directive with the new Directive. Do not lift the moratorium at any point until five years have passed, but do allow national governments to drag their heels in adopting the legislation, thereby ensuring a further year of unproductive baking.

Serve the pie triumphantly to foreign visitors in order to celebrate "a very biotechnology-friendly" resolution based on the EC communication "Life Sciences and Biotechnology: A Strategy for Europe" to prevent both a "brain drain" and "future dependency on the import of biotechnology products."

Your guests will be amazed as to the magnitude of the piecrust. They may be a little disappointed, however, when you penetrate the crust to reveal the paltry size of the filling that remains. You must explain that European agbiotech is not intended to feed anyone in Europe (or anywhere else for that matter). Furthermore, as in nouvelle cuisine, it is not the size of the helping that is important but the manner in which it is presented.

\section{Serving suggestions:}

In Europe, biotechnology usually comes with hot potatoes: wash down liberally with bitter wine of disillusion, followed by a few sour grapes, and some hard cheese. 